\title{
Four dangers in innovation policy studies - and how to avoid them
}

\author{
Kieron Flanagan* and Elvira Uyarra, \\ Manchester Institute of Innovation Research, \\ Alliance Manchester Business School, University of Manchester, Oxford Road, Manchester M13 9PL, UK. \\ Corresponding author email address: kieron.flanagan@manchester.ac.uk
}

Special Issue of Industry and Innovation forthcoming in 2016 "Innovation Policy: how can it best make a difference?" (eds) Poul Houman Andersen, Jesper Lindgaard Christensen, Ina Drejer and Jacob Rubæk Holm.

DOI: $10.1080 / 13662716.2016 .1146126$

Published version: http://www.tandfonline.com/doi/full/10.1080/13662716.2016.1146126

\begin{abstract}
The field of innovation policy studies is at a crossroads. It has clearly been influential. However, might it be losing the critical insight necessary to remain so in future? We discuss four dangerous tendencies seen in many innovation policy studies: idealising policy rationales and policy-makers; treating policies as tools from a toolbox; putting too much faith in co-ordination and intelligent design of "policy mixes"; and taking an atemporal approach to innovation policy. Based on these we identify some ways forward that, we argue, would deal better with the complex multi-actor dynamics, fundamental uncertainties and challenges to the implementation, co-ordination and evaluation of policies and which would make for more relevant and impactful innovation policy studies.
\end{abstract}

Keywords: Innovation Policy - Implementation - Policy Mixes - Evaluation - Co-ordination

\section{Introduction}

Morlacchi and Martin (2009) have argued that innovation policy studies are at a crossroads. Policy-makers are firmly persuaded of the importance of innovation. However, at the same time, it may be that innovation policy researchers have lost the critical reflexivity necessary to sustain their essential instrumental and critical roles in the longer term. Reference to policy is often limited to simple normative assertions (or "policy recommendations" as Perez (2013) disparagingly names them) about interventions suggested by systemic or evolutionary perspectives. In this paper, we build on and extend recent work by ourselves ${ }^{1}$ and others to highlight some possible dangers stemming from current approaches to innovation policy studies and to identify some ways forward that should help make innovation policy studies more relevant and impactful.

\footnotetext{
${ }^{1}$ This paper develops ideas and arguments first advanced in Flanagan et al (2011), extended in Uyarra and Flanagan (2013) and subsequently presented in a draft form at the Third Lundvall Symposium 2014: "Innovation policy - how can it make a difference?". We would like to express our gratitude to two anonymous reviewers and to the editors of and contributors to this special issue for all their insightful comments.
} 
We will argue that much innovation policy research exhibits a view of policy action which is not only unrealistic but which is also at odds with a dynamic approach to innovation. It rarely considers policy emergence and change, the agency of actors in relation to policy and outcomes, and their influence on institutionalisation processes. Instead it tends to treat policy makers as translators of theoretical rationales into action, to downplay the agency of other actors in relation to policy change and to offer superficial analyses of instruments as simple tools, neglecting implementation and policy learning and treating tensions, trade-offs and interactions between policies as something that can straightforwardly be designed out or co-ordinated away. Meanwhile it pays little attention to actual policy dynamics as they unfold over time.

We shall explore each of these tendencies and why they are dangerous in turn, and offer some thoughts as to positive ways forward. We believe better analysis is a precondition to better advice, and our aim is by no means to suggest that all is lost but rather to engender a positive and much-needed debate amongst innovation policy scholars about the means and ends of innovation policy research.

\section{Danger No. 1: Idealising theoretical rationales and policy makers}

Accounts of shifts in innovation policy (e.g. Ruivo 1994; Elzinga and Jamison 1995) tend to map changes in scholarly ideas about innovation onto policy rationales, and rationales onto instrument choices, implying that the former drive the latter. The idealised 'policy maker' is treated as a largely passive recipient of unproblematic and straightforward translated recommendations (Laranja et al 2008). In reality, scholarly concepts and the specific policy rationales held by policy makers are distinct, but interacting, bodies of knowledge. And whereas newer scholarly ideas tend to supplant older ones (e.g. market failure rationales are replaced by systemic rationales), policy rationales are more likely to accrete in layers because new policy ideas are implemented in a landscape shaped by older ones.

The mainstream policy studies literature treats ideas as but one amongst many factors shaping public policy. Work on the shaping of 'policy agendas' has led to new evolutionary accounts of policy and politics that share much common ground with evolutionary perspectives on technological change and innovation. Baumgartner and Jones (1993) discuss the generation and destruction of 'policy monopolies' characterised by a shared political understanding regarding the policy of interest and by institutional arrangements that tend to reinforce that understanding. Kingdon (1984) emphasises the role of 'policy entrepreneurs' - actors with a particular interest in the success of the policy. Meanwhile, some evolutionary economists have explored the co-evolutionary dynamics of innovation and policy or regulatory processes (Slembeck 1997; Witt 2003; Pelikán and Wegner 2003; Moreau 2004; Paraskevopoulou, 2010). Few links have yet been made between the two literatures, an interesting exception being the work of van den Berg and Kallis (2009).

The notion of policy entrepreneurship implies the active, intentional promotion of a policy idea - something that is by no means the sole preserve of government officials with formal powers. More broadly, the policy studies literature stresses that a multiplicity of actors, state and nonstate, individual, networked and corporate, may be involved in shaping policy. But whilst systemic and evolutionary accounts of innovation processes consider a wide range of actors, most are seen as passive in relation to public policy for innovation. We may have long since 
rejected the 'representative firm' but in prescriptive innovation policy studies we continue to treat policy as if it were the preserve of the representative 'policy maker' - even if at the same time we exhort that that policy-maker should be 'adaptive'. Others are only considered insofar as they contribute towards the performance of systemic 'functions' ${ }^{2}$. Yet, if public policy is part of the system then the agency of actors must be acknowledged not just in relation to innovation processes but also in relation to the processes through which policy problems are identified, solutions emerge and are put into practice.

Accounting for agency requires us to distinguish between actors and the roles that they play. Different types of actors may play similar roles in different national or regional contexts, or at different times (Wieczorek et al 2009; Aghion et al 2009; Flanagan et al 2011). Actors do not passively perform functions in a system - rather they play roles in processes, both innovation processes and policy/implementation processes. For example, Howells (2006) and Van Lente et al (2003) discuss the system function performed by 'intermediaries'. But 'intermediary' is not a type of actor but rather a role that may be played by a variety of actors of different types (and indeed simply to claim to be an intermediary is to play a role in the policy process).

Reviewing longstanding debates about structure and agency ranging from Parsons' early emphasis on internalised norms (Parsons 1937) and later systems theory (Parsons 1951) to Giddens' (1976) structuration theory, Barnes (2000) argues that structure-agency debates about voluntarist versus determinist explanations of social action miss the point that agency can only ever be social. 'New institutionalists' March and Olsen (2006) describe how institutions shape the roles actors play in multiple senses, including in the important indirect sense of providing beliefs and expectations which shape the ways in which actors choose to exercise their agency. This has often been taken by their followers to imply that institutions will overwhelmingly be a force for stability. However, stability may be explained by agency as much as by institutions (Geels, 2014). And change may emerge from the interpretation and reinterpretation of institutions by actors over time. Streeck and Thelen (2005) show how institutions evolve and are shaped by how actors - not just 'rule makers' but also 'rule takers' use them. As Lawson notes (2003), there is an ontological distinction between institutions and the practices that they shape or constrain. Not every actor will follow every rule at all times (see also Geels 2010). Variations in how actors interpret institutions, and in their expectations about how they might be enforced, leads to diversity in implementation and outcomes, and to 'deviations', intentional or not, which may contribute towards the breaking of path dependencies and the creation of new paths (Streeck and Thelen 2005).

\section{Danger No.2: Treating policies as tools from a toolbox}

Innovation policy studies tend to reflect the traditional interest of economic policy research (Slembeck 1997; Gunningham and Sinclair 1999; Howlett and Ramesh 2003) in the strengths and weaknesses, costs and benefits of individual policy instruments. Instruments are generally

\footnotetext{
${ }^{2}$ The literature seems confused as to whether functions are a property of actors and institutions or whether instead they are a property of the system itself (see e.g. Chaminade and Edquist 2006 versus Van Lente et al 2003). Hekkert et al (2007) seem to ascribe functions both to the system and to actors. Kuhlmann and Shapira (2006) are unusual in acknowledging the agency of system actors with respect to policy.
} 
seen as being substitutable at least in principle (Landry and Varone 2005). Public policy is treated as a toolbox from which the best tools for the job should be selected.

But policies are not tools. Even the most straightforward of interventions will demonstrate what sociologists of technology have called interpretive flexibility $^{3}$ - that is they carry different meanings from time to time, place to place, actor to actor. Instruments are interpreted differently by different actors and reinterpreted over time in the light of changing policy thinking. Even where rationales and design principles remain consistent, interventions are flexible to interpretation in practice. The causal mechanisms through which policies achieve their intended impacts may not be those intended by their designers but may be due to the hidden influence of those implementing the policies. Decisions taken by policy implementers may lead to significant variations in 'the same' instrument across time and space quite independently of differences in policy rationales and strategies (see e.g. Slembeck 1997). As Kay (2006) argues, policies cannot be analysed outside of the policy making process.

Instruments may vary so much across time and space that attempts at the rational metaevaluation of "what works" are rendered meaningless for all but the simplest of interventions. Unsurprisingly, the recent Manchester 'Compendium' review of evidence on innovation policies ${ }^{4}$ found no clear evidence that any class of innovation policy instrument studied works consistently from place to place or time to time. To take the case of cluster policies, Uyarra and Ramlogan (2016) found wide differences in policy outcomes resulting from variation not just in objectives and implementation but also due to context specific institutional configurations and policy path dependencies.

Policies, then, are not necessarily stable over time and across space whether in terms of rationales, goals or means. There must remain an irreducible uncertainty about which aspect of an instrument is actually responsible for any attributed effect (Bressers and 0'Toole 2005). Instruments may 'harden' over time into new actors and institutions that become part of the changed context in which future policy processes, and innovation processes, occur. And because policy plays rhetorical and performative, as well as instrumental, functions, instruments may be ends as well as means (Ringeling 2005). In short, values and interests are always bound up with instruments.

Most importantly, instruments do not work in isolation. Martin (2016, this issue) makes the analogy between the mix of policy instruments and the combination of prescription medications in the treatment of a single patient. He notes that drugs may interact with one another and with the underlying medical problem or problems in a highly complex manner. As a result the overall drug mix may be far from optimal, with a medication prescribed for one medical problem potentially counteracting the effect of a different drug aimed at treating another. Such interactions may also accumulate over time as new drugs are introduced in the treatment regime. To this analogy we would add that the same drug may elicit different responses from different individuals depending on physiology, diet, lifestyle, and other environmental factors. Decisions about the efficacy of any drug are made on the basis of averaging across the range of different responses exhibited during clinical trials. And all this complexity in practice is

\footnotetext{
${ }^{3}$ See e.g. Bijker et al (1989)

${ }^{4}$ See Edler et al (2016) and: http://innovation-policy.org.uk/
} 
exhibited by a highly standardised intervention - each dose being chemically identical. Few policy instruments are highly standardised interventions.

\section{Danger No.3: Too much faith in rational design and co-ordination}

Partly for the reasons discussed above, increasing attention is being paid to "policy mixes" rather than individual instruments considered in isolation. The early EU and OECD policy documents which pioneered the application of the policy mix concept to innovation policy analysis implicitly treated mixes as designed portfolios, the result of purposive action and coordination. This preoccupation remains evident in the more recent literature. Borrás and Edquist (2013) are centrally concerned with prescriptions for the design of instrument mixes, rather than with understanding the evolution of actual policy mixes as a precondition to making useful prescriptions. They do emphasise the importance of problems, objectives, activities and national policy styles in shaping instrument selection, but they downplay the flexibility of instruments themselves. Yet, as we have argued, policy instruments are not stable in terms of rationales, goals, use and impacts.

Nor does public policy pursue a single goal or even a coherent and hierarchical set of goals - it necessarily pursues a broad and ever-changing range of more or less explicit and implicit, final and intermediate goals and objectives. It must also react to urgent and often unforeseen problems. Some of these co-existing goals may only be obtained at the expense of others (Klappholz 1964). Thus policy rationales and policy goals, as well as means, may be in tension in a policy mix (see also del Rio and Howlett (2013) on the existence of "vertical" - that is means/ends - challenges to policy mix coherence, as well as "horizontal" tensions between instruments).

Improving the coherence and coordination of the broader policy mix affecting innovation processes has been a central preoccupation. For instance OECD (2010) suggest policy mix coherence should be thought of as the goal whilst coordination should be seen as the means of achieving that goal. Whilst the OECD acknowledges the significant co-ordination challenges presented by the sheer complexity and flexibility of the mix of policies likely to have an influence on innovation processes, Borrás and Edquist (2013) downplay these challenges. In their idealised approach, coherence will come from careful attention to problem identification and policy mix design. In their view, if the right decision framework is rationally applied to the question of instrument selection and layering, then a coherent mix should always result.

In contrast, Flanagan et al (2011) emphasise the emergent nature of policy mixes affecting innovation processes and their evolution over time. These policy dynamics co-evolve with other dynamics - such as budgetary, political and economic cycles. Goals, rationales and instruments emerge, evolve, are institutionalised or fade away. Systemic roles played by actors may change and actors will learn over time - meaning that the response of actors and processes targeted by policy action may change over time even where the intervention does not change. New policy instruments do not emerge into a vacuum but represent an intervention in a continuous stream of unfolding developments. Even with a policy mix that is largely the product of intentional design processes, it can never be certain to what extent theorised complementarities between policy interventions will be borne out in practice: at some point, instruments which may seem in principle to be complementary may begin to interact in unpredictable or negative ways in 
practice. The interactional characteristics of policy instruments "in the mix", whether theorised or observed, are always potentially transient.

Strong claims are made about the potential for 'systemic' instruments and 'strategic policy intelligence' tools such as foresight exercises to improve co-ordination and build shared and thus more coherent policy visions. These arguments are superficially plausible but evidence is scarce. And given such 'procedural' policy instruments (Howlett, 2005) have even more interpretive flexibility than the traditional 'substantive' levers of public policy, how can we really know that they are working? Such instruments actually introduce further complexity into the system to be co-ordinated, directly through the addition of new actors, new roles, new institutions, and indirectly by virtue of their inherently greater interpretive flexibility. For these reasons co-ordination will always remain a moving target ${ }^{5}$.

\section{Danger No.4: An atemporal approach to policy analysis}

Public policy unfolds over time. Policy dynamics will interact with other relevant dynamics electoral, budget and planning cycles, economic cycles, organisational life cycles - each with their own logics and imperatives (Kay 2006; Pollitt 2008). And as already noted, as these dynamics unfold and interact over time, goals, rationales and instruments will emerge, evolve and fade away. Actors will learn and change as the institutional context changes, discarding old roles and adopting new ones. Unintended outcomes of an intervention may even create new problems that displace the original policy problem (Bardach 2006).

Innovation scholars stress the importance of path dependency but rarely consider policy processes in this light. Yet past decisions will tend to constrain the range of options available for current decision makers (Steinmo 2003; Kay 2006; Bardach 2006). Policies are adopted into a context of pre-existing policy and actor/role mixes and institutional frameworks that have evolved over time (Uyarra 2010). For instance Valdaliso et al (2014) show how implementing a new regional development strategy necessarily involves building on a series of existing policies and organisational actors, including a landscape of supporting actors and structures built up over decades under earlier and very different rationales.

Each use of an instrument is an intervention in a continuous stream of events that influences the evolution of the instrument and will then be influenced by it (Pelikan 2003). All actors, not just policy-makers, learn from past experiences and learning-induced changes in behaviour over time may complicate attempts to evaluate cause-effect relationships (Witt 2003; Wegner 2003). The notion of the adaptive policy maker (Metcalfe 1994) exemplifies a view of policy learning that acknowledges the challenges of making and implementing policy in the face of economic uncertainty and path dependencies but discounts the uncertainties and path-dependent

\footnotetext{
${ }^{5}$ Lindblom (1958) offered a similar critique of the assumption that policy processes require active co-ordination efforts decades ago. With multiple implicit or explicit, and potentially conflicting policy goals at play in the messy real world, he (1959) famously argued that policy 'agencies' must of necessity proliferate in tandem with policy goals and that the best that may be hoped for is dynamic mutual adaptation. Systemic instruments and strategic intelligence may be plausible insofar as they promote such mutual adaptation.
} 
dynamics inherent in the policy process itself. In particular it neglects implementation: if anything, it is adaptive implementers that are needed.

\section{Conclusion: the way forward?}

In order to be useful, innovation policy analysts should abandon our linear model of public policy (Martin 2010 and Flanagan et al 2011 both make the analogy between innovation processes and policy processes) and its associated notions: instruments as tools; mixes as portfolios; and the view that rational policy co-ordination is easily achievable. The approach to public policy taken in many innovation studies is to us reminiscent of 1950s welfare economics. Geels (2010) provocatively suggests that this may be symptomatic of the fact that this supposedly interdisciplinary area is, in reality, dominated by economists. Similarly, Perez (2013: p.3) argues that the design of effective policies "in these troubled times" requires that evolutionary economics and innovation systems studies become more interdisciplinary by truly incorporating a historical view.

We have argued from the perspective that policy processes and entrepreneurial processes of discovery and innovation have similar evolutionary dynamics, ones that are uncertain (in the Knightian sense) rather than deterministic. Decades of implementation studies suggest that, whilst ideas are the currency of policy debates, whether a big idea works in theory is less important to a successful outcome than are context-sensitive decisions about implementation taken by well-informed, empowered actors on the ground. And the insights scholars have developed from decades of careful study of innovation processes are often not well suited to the job of generating strong policy prescriptions. They are, however, very well suited to highlighting possibilities and challenges for policy implementation, and this is surely where more of our efforts should be focused.

Adopting a genuinely evolutionary approach to innovation policy requires "a fundamental appraisal of the purpose and limitations of policy action" (Metcalfe and Georghiou 1997). This has to start from a fuller acknowledgement of the potentially limited scope for policy action to influence and direct the evolution of economies. Complex interactions between mutually interdependent subsystems mean that a system's response to even small changes may be highly disproportionate (Sanderson 2009). Greater knowledge of the system by no means guarantees better prediction or control as the observed system does not stand still but is constantly changing and reinterpreting itself (Geyer and Rihani 2010). Co-ordination will always remain a profound challenge and attempts at steering will themselves increase complexity. Mutual adaptive co-ordination, informed by contextual knowledge, is a more realistic aim than topdown steering.

Understanding change and agency in institutional transformation is challenging. Path dependent policy dynamics do not preclude change but rather imply a tendency towards bounded change, wherein certain alternatives become less viable or less attractive (Pierson 2000). Sotarauta and Pulkkinen (2011; p.102) ask how actors can innovate and renew institutional settings "if their beliefs and actions are all determined by the very institutional environment they wish to change"? Innovation policy studies could usefully pay more attention to the role of agency in making and breaking policy path dependencies and the roles institutions play in enabling and constraining action. Edler and James (2015) provide a partial illustration of 
how agency might be tacked in their recent study of the evolution of the Framework Programme.

Grappling with policy complexity will require a much better understanding of how learning and adaptation takes place in real innovation policy systems (Morgan 2013). This includes learning from failure, active experimentation and trial and error (see e.g. Potts 2009). Experimentation and strategy in an evolutionary sense emphasise "creating choices, keeping options open and making the tree of possibilities as bushy as possible at any point in time" (Beinhocker 2006: 339). Allowing some freedom of action for local experimentation in implementation thus becomes important.

A truly evolutionary approach to innovation policy must recognise that all actors in policy processes can only ever be adaptive. The positive role innovation policy studies can play here is not in identifying the right configuration for the system or making empty exhortations to be 'adaptive', but rather in drawing attention to uncertainties and trade-offs, such as the balance between decentralised experimentation and the need to learn and rapidly transfer lessons, or the wider hidden complexities, uncertainties, and trade-offs between inevitably conflicting policy goals, encouraging open debate and shedding light on the hidden politics behind innovation policy choices. New approaches to innovation policy that aspire to greater contextsensitivity and experimentation, such as smart specialisation (Foray, 2014; Morgan, 2013), provide a potential platform for such debates. However it is by no means certain that the necessary debates will occur: innovation policy scholars have a role to play in ensuring this happens.

The complexity inherent in policy processes undoubtedly limits the scope for co-ordination and evaluation. At the same time it highlights crucial roles for knowledge, learning and adaptation. If we expect evaluations to be able to confirm 'what works' in an area of high complexity such as innovation policy, then we are surely expecting too much. But the rich tradition of evaluation studies in research and innovation policy should provide an excellent basis for building insights into the influence of contextual factors on policy outcomes, and on the roles of policy implementers in shaping those outcomes.

All this suggests a need for a richer empirical understanding of actual 'policy histories' than is generally seen in innovation policy research. Garud et al (2010) argue that understanding agency requires a 'narrative approach' that follows the actors and studies processes in real time, one which avoids the treatment of a sequence of events as inevitable. As with the decades of careful innovation case studies from which so much of our understanding of innovation dynamics stems, policy histories would ultimately need to be compared and interpreted in the light of theory and other data. The work of Avnimelech and Teubal (2004) on Israeli cluster development (richly characterising a long-term process of co-evolution involving the business sector, technology policies, venture-capital, etc.), Sotarauta's (2012) account of the 20-year evolution of Finnish 'cluster-flavoured' innovation policies or the work of Valdaliso et al (2014) on the imposition of policies rationalised under the concept of 'smart specialisation' onto a rich landscape of existing actors, structures and institutions shaped by policies justified under earlier rationales, provide glimpses of what appreciative policy histories might look like.

Innovation is of course but a potential means to the achievement of many different goals of public policy. Calls for mission- or challenge-oriented approaches (Mazzucato, 2016 this issue) 
reflect this truism. Innovation processes also create multiple problems that public policies may be expected to address. Concerns about the quality and direction, as well as the quantity of innovation, were never far from the mind of the founders of the field (see e.g. Nelson 1977) but recent innovation policy studies seem to have somewhat lost sight of them. It seems to us that some of the recent work on sectoral innovation policies in areas such as energy, and on transitions in socio-technical systems (see e.g. Geels 2010, 2014) does demonstrate how insights from innovation studies can be applied in a more critical, analytical and interdisciplinary manner when oriented towards a more specific and meaningful policy goal than simply one of "more innovation".

Innovation scholars will surely continue to suggest actors, processes and institutions as targets for policy action, which in turn may imply, or at least inspire, consideration of a particular kind of intervention. But an evolutionary view of innovation policy can never be predictive or firmly prescriptive about specific instruments or mixes. Acknowledging these limitations would make innovation policy studies more useful: in the words of Richard Nelson $(1977, \mathrm{p} 18)$ "the coin of rational analysis is likely to be devalued by trying to achieve what cannot be bought by rational coin".

We can best play our instrumental and critical roles (Morlacchi and Martin 2009) by focusing much more effort on understanding how implementation, experimentation and adaptive learning affect the impacts of policy interventions driven by real goals. Such insights, coupled with our rich understanding of innovation dynamics, would put us in a unique position to comment on the constraints on and potentialities for policy action. Rather than trying to answer once and for all what policies or mixes should be implemented, we should be stimulating and supporting an open and on-going debate about which policies could be implemented and how, and about the inevitable trade-offs and tensions between means and ends in the constantly evolving policy mix for innovation. This implies a more consistently engaged but at the same time more consistently critical approach to the policy process and to policy makers than has been apparent in recent times.

\section{Bibliography}

Aghion, P. David, and P.A. Foray, D. 2009. 'Science, technology and innovation for economic growth: Linking policy research and practice in 'STIG Systems" Research Policy 38: 681-693.

Avnimelech, G. and Teubal, M. 2004. 'Venture capital start-up co-evolution and the emergence \& development of Israel's new high tech cluster', Economics of Innovation and New Technology, Taylor and Francis Journals, 13; 33-60.

Bardach, E. 2006. 'Policy Dynamics' in Moran M, Rein M and Goodin RE (eds) The Oxford Handbook of Public Policy. Oxford University Press, Oxford.

Barnes, B. 2000. Understanding Agency: Social Theory and Responsible Action, Sage.

Baumgartner, F R., and Jones, B.D. 1993 Agendas and instability in American politics. University of Chicago Press, Chicago, IL. 
Beinhocker, E. D. 2006. The Origin of Wealth: Evolution, Complexity and the Radical Remaking of Economics (Random House, London).

Bijker, W., Hughes, T. and Pinch, T. (eds) 1989. The Social Construction of Technological Systems. MIT Press, Cambridge MA.

Borrás, S. and Edquist, C. 2013. "The Choice of Innovation Policy Instruments" CIRCLE Working Paper No 2013/04, Centre for Innovation, Research and Competence in the Learning Economy (CIRCLE), Lund University.

Bressers, H.A. and O'Toole, L.J. 2005. Instrument selection and implementation in a networked context. In Eliadis, F. P., Hill, M. and Howlett, M.P. (eds). Designing government: from instruments to governance, McGill Queens Univ Press.

Chaminade, C. and Edquist, C. 2006. From theory to practice. The use of the systems of innovation approach to innovation policy, in Innovation, Science and Institutional Change. A Research Handbook, Oxford University Press, Oxford.

Del Rio, P., and Howlett, M. P. 2013. Beyond the 'Tinbergen Rule' in Policy Design: Matching Tools and Goals in Policy Portfolios. Lee Kuan Yew School of Public Policy Research Paper, (1301).

Edler, J., and James, A. 2015. 'Understanding the emergence of new science and technology policies: Policy entrepreneurship, agenda setting and the development of the European Framework Programme', Research Policy 44: 1252-1265.

Edler, J., Cunningham, P., Gok, A. and Shapira, P. 2016. (eds.) Handbook of innovation policy impact. Edward Elgar.

Elzinga, A. and Jamison, A. 1995. 'Changing policy agendas in science and technology', in Jasanoff S (ed), Handbook of science and technology studies. Sage, Thousand Oaks, Calif and London.

Flanagan, K., Uyarra, E. and Laranja, M. 2011. 'Reconceptualising the 'policy mix' for innovation.' Research Policy 40: 702-713.

Foray, D., 2014. Smart Specialisation: Opportunities and Challenges for Regional Innovation Policy. Routledge.

Garud, R., Kumaraswamy, A. and Karnøe, P. 2010. 'Path Dependence or Path Creation?' Journal of Management Studies, 47: 760-774.

Geels, F. W. 2010. 'Ontologies, socio-technical transitions (to sustainability), and the multi-level perspective’ Research policy, 39: 495-510.

Geels F.W. 2014. 'Reconceptualising the co-evolution of firms-in-industries and their environments: Developing an inter-disciplinary Triple Embeddedness Framework', Research Policy 43: 261-277.

Geyer, R. and Rihani, S. 2010. Complexity and Public Policy: A New Approach to 21st Century Politics, Policy and Society. London: Routledge.

Gunningham, N. and D. Sinclair 1999. 'Regulatory pluralism: designing policy mixes for environmental protection' Law \& Policy 21: 49. 
Hekkert, M. P., Suurs, R.A., Negro, S.O., Kuhlmann, S. and Smits, R.E. 2007. 'Functions of innovation systems: a new approach for analysing technological change' Technological Forecasting \& Social Change 74: 413-432.

Howells, J. 2006. 'Intermediation and the role of intermediaries in innovation' Research Policy 35: 715-728.

Howlett, M. 2005. "What is a policy instrument? Policy tools, policy mixes, and policyimplementation styles" in Eliadis, P., Hill, M. and Howlett, M. (eds), Designing Government: from instruments to Governance. McGill-Queens University Press, Montreal.

Howlett, M. and Ramesh, M. 2003. Studying public policy: policy cycles and policy subsystems (Second Edition). Oxford University Press, Oxford.

Kay, A. 2006. The Dynamics of Public Policy: Theory and Evidence. Edward Elgar Publishing, Cheltenham.

Kingdon, J. 1984. Agendas, alternatives and public policies. Longham, New York

Klappholz, K. 1964. 'Value Judgements and Economics' The British Journal for the Philosophy of Science 58: 97-114.

Kuhlmann, S. and Shapira, P. 2006. How is Innovation Influenced by Science and Technology Policy Governance? Transatlantic Comparisons. In: Hage, J. / Meeus, M. (eds.): Innovation, Science, and Institutional Change; A Research Handbook. Oxford University Press, Oxford.

Landry, R. and Varone, F. 2005. Choice of policy instruments: Confronting the deductive and the interactive approaches. In Eliadis, F. P., Hill, M. and Howlett, M.P. (eds). Designing government: from instruments to governance, McGill Queens Univ Press.

Laranja, M., Uyarra, E. and Flanagan, K. 2008. 'Policies for science, technology and innovation: Translating rationales into regional policies in a multi-level setting' Research Policy 37: 823835.

Lawson, T. 2003. 'Institutionalism: On the Need to Firm up Notions of Social Structure and the Human Subject' Journal of Economic Issues, 37: 175-207.

Lindblom, C.E. 1958. 'Tinbergen on Policy-Making', Journal of Political Economy, 66: 531-538.

Lindblom, C.E. 1959. The Science of "Muddling Through" Public Administration Review, 19: 7988.

March, J.G. and Olsen, J.P. 2006. The Logic of Appropiateness in Moran M, Rein M and Goodin RE (eds) The Oxford Handbook of Public Policy. Oxford University Press, Oxford.

Martin, B. 2010. Science policy research - having an impact on policy?, Office of Health

Economics Seminar Briefing No.7, December 2010.

Martin, B. 2016. Industry and Innovation (this issue)

Mazzucato, M. 2016. Industry and Innovation (this issue)

Metcalfe, J. S. 1994. 'Evolutionary economics and technology policy' The Economic Journal: 931944.

Metcalfe, J.S. and Georghiou, L. 1997. 'Equilibrium and evolutionary foundations of technology policy' STI review, no.22. 
Moreau, F. 2004. 'The role of the state in evolutionary microeconomics' Cambridge Journal of Economics 28: 847-74.

Morgan, K. 2013. Path Dependence and the State: The Politics of Novelty in Old Industrial Regions. In P. Cooke (ed) Re-framing Regional Development: Evolution, Innovation and Transition. Routledge, pp. 318-340.

Morlacchi, P. and B. R. Martin 2009. 'Emerging challenges for science, technology and innovation policy research: A reflexive overview' Research Policy 38: 571-582.

Nelson, R. R. 1977. The moon and the ghetto, WW Norton \& Company, London.

OECD, 2010. 'Chapter 4 The Innovation Policy Mix', Science, Technology and Industry Outlook 2010. OECD, Paris.

Paraskevopoulou E., 2010. 'Analyzing the institutional innovation process through an evolutionary lens', paper presented at the International Schumpeter Society Conference 2010 on Innovation, Organisation, Sustainability and Crises, Aalborg, June 21-24, 2010.

Parsons, T. 1937. The Structure of Social Action, Free Press, Glencoe.

Parsons, T. 1951. The Social System, Free Press, Glencoe.

Pelikan, P. 2003. 'Why economic policies need comprehensive evolutionary analysis' in Pelikan, P. and Wegner, G. (eds). The Evolutionary Analysis of Economic Policy. Edward Elgar, Cheltenham.

Perez, C. 2013. 'Innovation systems and policy: not only for the rich?' Working Papers in Technology Governance and Economic Dynamics no. 42. Tallinn University of Technology, Tallinn.

Pierson, P. 2000. 'Increasing Returns, Path Dependency, and the Study of Politics', American Political Science Review 94: 251-67.

Pollitt, C. 2008. Time, Policy, Management: governing with the past, Oxford University Press, Oxford.

Potts, J. 2009. 'The innovation deficit in public services: The curious problem of too much efficiency and not enough waste and failure', Innovation: Management, Policy \& Practice, 11: $34-43$.

Ringeling, A.B. 2005. 'Instruments in four: the elements of policy design' in P Eliadis, MM Hills, M Howlett (eds) Designing Government: From Instruments to Governance. McGill-Queens University Press, Kingston, Ontario.

Ruivo, B. 1994, 'Phases' or 'paradigms' of science policy?' Science and Public Policy 21:157-164.

Sanderson, I. 2009. 'Intelligent Policy Making for a Complex World: Pragmatism, Evidence and Learning', Political Studies 57: 699-719.

Slembeck, T. 1997. 'The Formation of Economic Policy: A Cognitive-Evolutionary Approach to Policy-Making' Constitutional Political Economy 8: 225-254.

Sotarauta, M. and Pulkkinen, R. 2011. 'Institutional Entrepreneurship for Knowledge Regions: In Search of a Fresh Set of Questions for Regional Innovation Studies' Environment \& Planning C. 29: $96-112$. 
Sotarauta, M. 2012. 'Policy learning and the 'cluster-flavoured innovation policy' in Finland' Environment and Planning C: Government and Policy, 30: 780 - 795.

Steinmo, S. 2003. 'The evolution of policy ideas: tax policy in the 20th century' The British Journal of Politics and International Relations 5: 206-236.

Streeck, W. and Thelen, K. 2005. Beyond Continuity: Institutional Change in Advanced Political Economies. Oxford University Press.

Uyarra, E. 2010. 'What is evolutionary about regional systems of innovation?', Journal of Evolutionary Economics 20: 115-137.

Uyarra, E. and Flanagan, K. 2013. 'Reframing regional innovation systems: Evolution, complexity and public policy' in Cooke, P. (ed). Reframing Regional Development: Evolution, Innovation \& Transition, Routledge.

Uyarra, E. and Ramlogan, R. 2016. 'The Effects of Cluster Policy on Innovation' in Edler, J., Cunningham, P., Gok, A. and Shapira, P. (eds.) Handbook of innovation policy impact. Edward Elgar.

Valdaliso, J.M., Magro, E., Navarro, M., Aranguren, M.J. and Wilson, J.R. 2014. 'Path dependence in policies supporting smart specialisation strategies'. European Journal of Innovation Management, 17: pp.390-408.

Van den Bergh, J. and Kallis, G. 2009. 'Evolutionary Policy'. Papers on Economics and Evolution. Max Planck Institute of Economics, Jena.

van Lente, H., Hekkert, M. Smits, R. and Waveren, B. 2003. 'Roles of systemic intermediaries in transition processes' International journal of Innovation management 7: 247-280.

Wegner, G. 2003. 'Evolutionary markets and the design of institutional policy', in Pelikan, P. and Wegner, G. (eds). The Evolutionary Analysis of Economic Policy. Edward Elgar.

Wieczorek, A.J., Hekkert, M.P. and Smits, R. 2009. 'Contemporary innovation policy and instruments: challenges and implications', Innovation Studies Utrecht (ISU) Working Paper Series No. 09.12. Universiteit Utrecht, Utrecht.

Witt, U. 2003. 'Economic policy making in evolutionary perspective' Journal of Evolutionary Economics 13: 77-94. 